\title{
KÖPRÜ YAPILARINDA YERALTI RADARI (YR) VE KABLOSUZ SENSÖR AĞI (KSA) İLE OLUŞTURULAN SAĞLIK DEĞERLENDIRME SISTEMI
}

\author{
APPLICATION OF GROUND PENETRATING RADAR (GPR) AND \\ WIRELESS SENSOR NETWORKS (WSN) ON BRIDGE HEALTH \\ ASSESSMENT
}

\author{
Gökhan KILIÇ¹
}

Öz

$\mathrm{Bu}$ yayında belirlenen örnek çalışma köprüsü üzerinde gelişmiş Tahribatsız Muayene Teknikleri (TMT): Yeraltı Radarı (YR) ve Kablosuz Sensör Ağı (KSA) kullanılarak elde edilen sonuçlar detaylı biçimde ele alınmıştır. Köprülerin yapısal bilgileri olarak donatının yeri, nem bilgisi ve herhangi bir noktasındaki sapmaları belirlenir. Özet olarak, yukarıda bahsedilen tekniklerin kullanımı ile köprülerin yapısal bütünlük ve genel fonksiyonelliklerinin değerlendirilmesi ve gözetimi için bir tümleşik model/yaklaşım geliştirilmek istenmiştir. $\mathrm{Bu}$ çalışma, potansiyel olarak köprü yapılarının mekanik ve fiziksel davranışlarının daha iyi bir şekilde anlaşılmasına yönelik katkı sağlayabilir ve sonuç olarak öngörülen yaşam sürelerini ve işlevselliklerini değerlendirebilir. Bu mekanizmanın gelecekte mühendisler tarafından betonarme köprüler üzerinde detaylı yapısal değerlendirmeler sunmak için kullanılabileceği düşünülmektedir.

Anahtar Kelimeler: Köprü, Sağlık Gözetimi ve Değerlendirmesi, Yeraltı Radarı (YR), KSA

\section{ABSTRACT}

This paper presents the results of the application of several Non-Destructive Techniques (NDT): Ground Penetrating Radar (GPR) and Wireless Sensor Networks (WSN) on a Case Study Bridge. This provides crucial structural information such as rebar position, moisture ingress and deflection. The results of all of the above are compared in order to identify the portion of the bridge which had undergone the greatest amount of deterioration. This process forms the basis for the integrated bridge health mechanism proposed by this paper. This mechanism can be used to provide the detailed structural evaluatio for reinforced concrete bridges by future engineers.

Keywords: Bridge, Health Monitoring and Assessment, Ground Penetrating Radar (GPR), WSN

\footnotetext{
${ }^{1}$ İzmir Ekonomi Üniversitesi, İnşaat Mühendisliği Bölümü, gokhan.kilic@ieu.edu.tr (Sorumlu Yazar)
} 


\section{GİRIȘ}

Mühendislik yapıları, doğal ve çevresel olgular (deprem, sel baskınları, donma, çözünme vb.) nedeniyle yapısal sağlık problemleri ile karşı karşıya kalırlar. Köprü yapılarının sağlık durumunu hızlı ve güvenilir bir şekilde değerlendirebilmesi problemi önemli ve acil çözüm bulunması onlarca yıldır mühendislerin ve araştırmacıların ilgi odağı olmuştur. Köprü yapıları toplum hayatının ekonomik, sosyal ve çevresel yönlerinde önemli bir rol oynarlar. Günümüzde köprülerin yapısal sağlık incelemesi genellikle gözlemsel (kişisel yargı ve tecrübeye dayal1) ve basit aletlerle (beton test çekici, dürbün, mezura, kamera, tebeşir... vb.) yapısal bütünlük ve genel fonksiyonellikleri ortaya çıkarmak için kullanılmaktadır. Ancak bu yöntemler köprünün sağlığını tam kapsamlı olarak göstermez ve yapısal hasarın kritik göstergeleri göz ardı edilebilir.

Köprü yapılarının mevcut durumlarını tahribatsız, hızlı ve güvenilir şekilde değerlendirilebilmesi önemli ve acil çözümler gerektiren konulardan biridir. Tahribatsız teknolojiler, bu gereksinimlere etkili ve hılı bir şekilde cevap veren yöntemlerden birisidir. Ayrıca, bu teknikler, betonarme köprü yapılarda zamanla ortaya çıkabilecek sorunların değerlendirilmesinde de kullanılabilir. Belirli aralıklarla köprü yapılarının incelenmesiyle yapı özelliklerinin nasıl değiştiğini izlemek mümkündür. Bu yöntemler, beton özelliklerinin tespiti ve kalite kontrol amaçlarıyla kullanılabileceği gibi yapının inşa aşamasında ortaya çıkabilecek sorunlara karşı önlemler alınabilmesi için inşa sürecinde de kullanılabilir.

Ulaşım ve tesisat (doğalgaz, su, elektrik, atık su... vb.), köprüler ağının ve bir toplumun temel unsurlarıdır ve bunların ekonomik, endüstriyel zenginliği için kritik öneme sahiptir. Bu itibarla, kusurlu olmaları halinde maliyetli olmalarının ve potansiyel olarak felakete yol açmalarının önlenmesinde ve maksimum hizmete uygun ömre sahip olmalarının sağlanmasında, düzenli bakım denetim ve değerlendirmeleri hayati önem taşır. Çevresel korozyon, trafik ve rüzgâr yükü, depremler ve yaşlanma, köprülerin yapısal hasar görebilirliği üzerinde etkilidir ve bunları belirlemek için yeni test tekniklerine talep vardır. Yapısal sağlık izlenimi, günümüzde kullanılan köprülerin yapısal bütünlüğünün korunması için kritik öneme sahiptir. Köprüler, toplumun altyapı varlığının ve mirasının önemli bir parçasını teşkil eder ve inşaat malzemelerinin doğal bir bozulma sürecine tabidirler ki bu da büyük mali sonuçlara ve en kötü durumunda ölümle sonuçlanan felaketlere yol açabilmektedir.

Sonik/ultrasonik, elektromanyetik, elektrikli ve kızıötesi termografi [1], [2] gibi Tahribatsız Muayene Teknikleri (TMT) değerlendirme yöntemlerinin her biri, teste tabi tutulan yapının [3] fiziksel durumuna ilişkin bilgi verebilir fakat bu zamana kadar çalışmalar ağırlıklı olarak laboratuvarda gerçekleşmiştir [4], [5], [6]. TMT zaman ve para açısından yüksek maliyetlidir fakat devam eden teknolojik gelişimiyle bu maliyetler azalmakta ve bu da Yeraltı Radarı (YR) ve Kablosuz Sensör Ağı (KSA) gibi teknolojilere olan ilgiyi artırmaktadır. Mühendislere köprü bakımıyla ilgili karar almada ihtiyaç duydukları bilgilerin verilmesi için, bu teknolojilerle elde edilen veriler, daha geleneksel olan araştırma yöntemlerinden derlenen bilgilerle birlikte ele alınır.

TMT yöntemlerinin bir tümleşik kullanılmasıyla mümkün olan en iyi bilgi toplamanın gerçekleşeceği kabul edildiği için, TMT'ye yönelik yeni bir yaklaşım oluşmuştur. Niçin böyle olduğunu örneklerle açıklamak gerekirse, YR incelemesinin güvenilirliği suyun olduğu (az bir dereceye kadar) yerlerde ve öznelciliğge karşı zayıf iken [7], [8], ultrasonun güvenilirliği de nemin meydana geldiği durumlarda zayıftır fakat elastiklik modülünün değerlendirilmesinde kullanılabilir. İkisi birlikte daha kapsamlı veriler sağlayabilirler. Bazı araştırmacılar bunun 
beton dayanımı değerlendirmesi açısından ve hem teşhis amaçlarına hem de ölçüm gürültüsünün minimize edilmesine yönelik tespit ve görselleştirme amaçları [5] için ilerlemenin yolu olduğunu düşünürler [3], [9]. Tanı sonucunun gelişmiş olduğu görülebilirse, TMT tekniklerinin bir tümleşik kullanılmasının ekstra mali gereklilikleri kabul görebilir [6]; yani kombine tekniklerle toplanan ek bilgiler lüzumsuz olmaktan ziyade faydalı olabilir. Bu yayının amacı, inceleme yapıp betonarme yapıların teşhisinde TMT yöntemleri kullanılması bağlamında tanımlı bir yaklaşım önermektir.

Şu an TMT yöntemleriyle ilgili iki ana sorun mevcuttur:

- Değerlendirmeler çoğu kez TMT yöntemi kullanılarak yapılsa da, pek çok bozulma nedenine (kirişlerin katman ayrılması, nem girişi vs.) önemli derecede maruz kalan köprü yapılarında TMT yönteminden fazlasının kullanılması çok daha etkili olacaktır [6], [10].

-Daha eski olan köprü yapılarında ise çok az belge (yapısal raporlar, çizimler vs.) mevcuttur veya hiç belge yoktur ve bu durum söz konusu örnek olay çalışması için de tam olarak geçerlidir. Geleneksel test yöntemleri ile bu soruna hitap edilmez. Bunun sonucu olarak, donatı ve kiriş konumlandırması gibi kritik bilgiler bilinmemekte ve bu da yapısal tasarım mühendislerinin sayısal yöntemler kullanarak bu köprülerin yapısal davranışlarını güvenilir bir şekilde modelleyip simüle etme kabiliyetlerine sınırlama getirmektedir.

$\mathrm{Bu}$ yayın, literatürdeki bu boşluğu doldurmayı amaçlamakta ve bu sebeple birbiriyle tümleşik halindeki farklı TMT ve parametrik çalışma sonuçlarının etkinliklerini değerlendirerek, bir köprü sağlıği değerlendirme stratejisi sunmaktadır. Bu belge, köprü değerlendirmesindeki güvenilirliklerinden ötürü seçilen YR ve KSA teknikleri kullanılarak örnek köprü üzerinde uygulanan yöntemin sonuçlarını sunmaktadır. Önceden de belirtildiği gibi, örnek olay çalışmasındaki köprüye ilişkin sınırlı bir dokümantasyon mevcuttur ve sonuç olarak yukarıda belirtilen teknikler kullanılarak gerçekleştirilen çalışmaların sonuçları bu belgede mevcut olsa da, köprünün yeni inşa edildiği zamandan bu güne bozulma meydana gelip gelmediğinin değerlendirilmesi mümkün değildir [6], [9], [11], [2], [8], [12], [13].

İyileştirici çalışma yapılabilmesine ilişkin bilinçli kararlara esas teşkil edecek detaylı bir yapısal rapor oluşturulması için, bu tümleşik yaklaşım yapısal sağlığı değerlendirme aracı olarak kapsamlı bir köprü gözetim planına dâhil edilebilir. Ayrıca, bu yaklaşım donatı konumlandırması gibi bilgiler sağlar ve hâlihazırda mevcut olan başka bilgiler yoksa yapıda saklı olan anormallikleri (çatlaklar, katman ayrılması, nem girişi ve oyuklar) tanımlar.

\section{2. ÖRNEK ÇALIŞMA KÖPRÜSÜ}

Pek çok köprü yapısında olduğu gibi örnek çalışma köprüsü yapısı hakkında da çok az bilgi mevcuttur. Bu durum, tümleşik köprü sağlı̆̆ı mekanizmasının uygulanmasının uygun olup olmadığının anlaşılması ve diğer köprülerde kullanılmaya uygunluğu açısından, onu bu örnek olay çalışması için ideal köprü seçimi yapar (Şekil 1). 


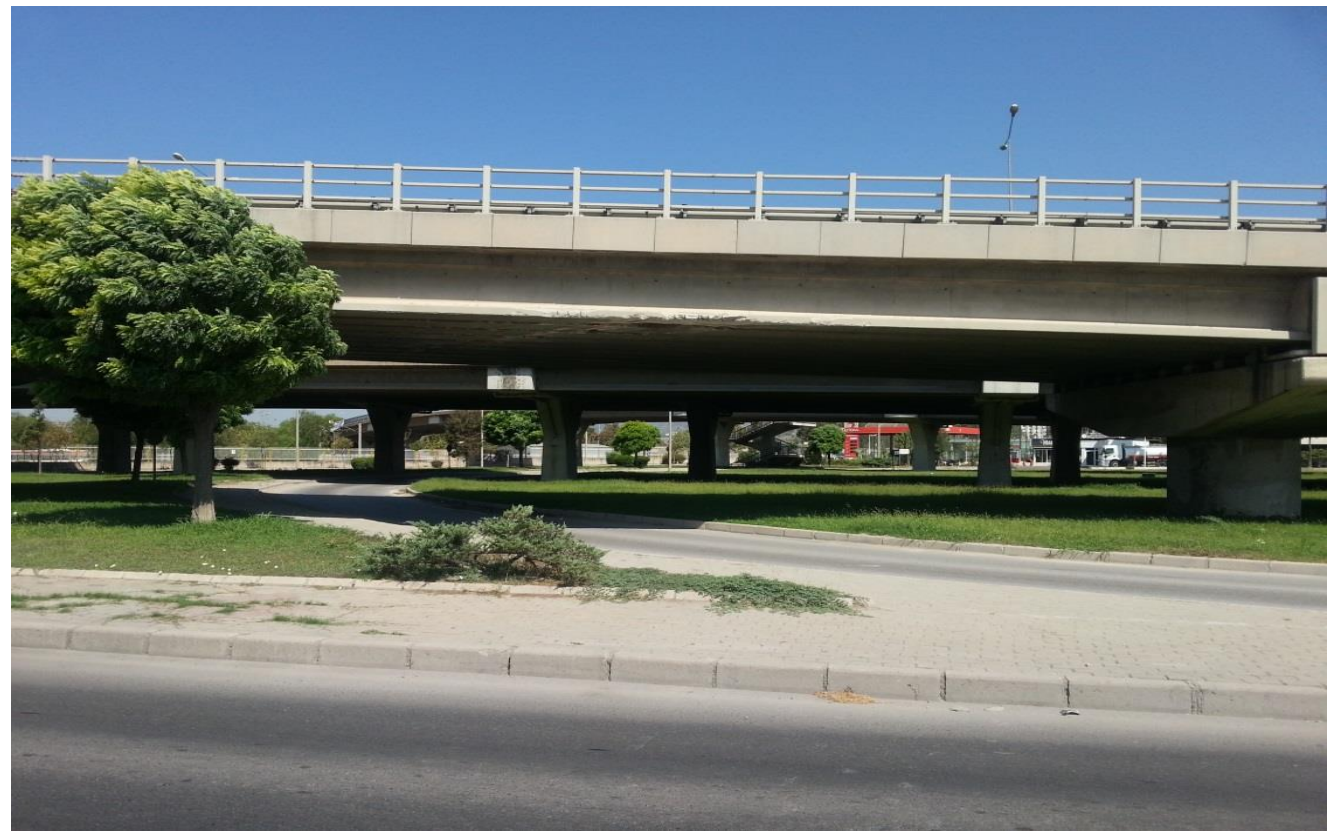

Şekil 1. Örnek Çalışma Köprüsünün genel görünüşü

Örnek açlışma köprüsü geniş açıklıklı ve öngermeli kirişlerden oluşan bir köprüdür. Örnek açlışma köprüsü Şekil 1'de alt bağlantı yolu ve aynı şekilde, üst bağlantı yolu proje eksenine gelecek şekilde yerleştirilmiştir.

\section{METODOLOJI}

Metodoloji birkaç TMT uygulamasından oluşur: gözle muayene, YR ve KSA. Köprünün yapısal sağlığına ilişkin doğru bir anlayış elde edilmesi için sonuçları karşılaştırılır.

\subsection{GÖZLE MUAYENE}

Görsel muayene, geleneksel bir yap1 denetim yöntemidir ve diğer yap1 sağlı̆̆1 gözetim yöntemlerindeki avantajlara rağmen hala kullanılmaktadır. Görsel muayene, gözle görülebilen yüzeysel kusurlarla sınırlı olduğu için tümüyle yeterli değildir ve insan hükmüne tabi oluşundan ötürü muhtemel hatalara yol açar [17].

Gözle muayene, hem bariz (beton ayrışması, çatlaklar, boşluklar) hem bariz olmayan (nem, çelik donatı korozyonu) önemli problemler gibi herhangi bir yüzeysel yapı problemi için masrafsız ve hızlı bir tespit yöntemidir. Ancak detaylı sonuçlar vermez ve diğer tekniklerle birleştirilmesi gerekir. Yazar tarafından 15 Kasım 2013 tarihinde bir gözle muayene gerçekleştirilmiştir. İncelenen döşeme tabakası alt yüzeyi ve alttaki taşıt yolu gibi her bir eleman için, çatlama, dökülme, açıkta kalan destek, sızıntı ve paslanma için dokunma mesafesinde gözle muayene yapılmıştır. Bu incelemenin sonuçları 4. bölümde sunulmaktadır.

\subsection{YR İNCELEMESI}

Yeraltı radarı (YR), köprü ve tünel gibi yapıların tahribatsız olarak değerlendirilmesi ve gözetimi için olan oturmuş ve başarılı bir yöntemdir. YR; yapı mühendisliği, tüneller, beton yapılar ve köprüler gibi inşaat mühendisliği yapılarının denetimine yönelik girişimsel olmayan, sürekli ve yüksek hızlı bir araç haline gelmiştir. Bu teknik, köprü sağlı̆̆ değerlendirmesinde bakım acentelerinin köprü yapıları hakkında detaylı bilgi elde etmelerine 
imkân verir. YR'nin köprü döşemesi ve yer altı tesisatlarının konumu hakkında her zaman bilgi verdiği ortaya konulmuştur. YR kapsamında tanımlamaya yönelik olan özellikler donatıyı ve durumunu içerir ve uzunluğu, çatlakları ve kapsamlarını, çökmeyi, nem mevcudiyetini, katman ayrılmasını, malzeme tabakalarını, oyukları ve bunların yanı sira kirişler, kolonlar ve köprü kenar ayakları gibi diğer yapılardaki sızıntılar, çatlaklar ve çökmeler gibi özellikleri kapsar [15], [16], [17], [18], [12], [19], [20] , [21].

İnceleme, 2 GHz Yer Radarı Anteni (Bkz.Şekil 2) kullanılarak 17 Kasım 2013 tarihinde gerçekleştirildi.
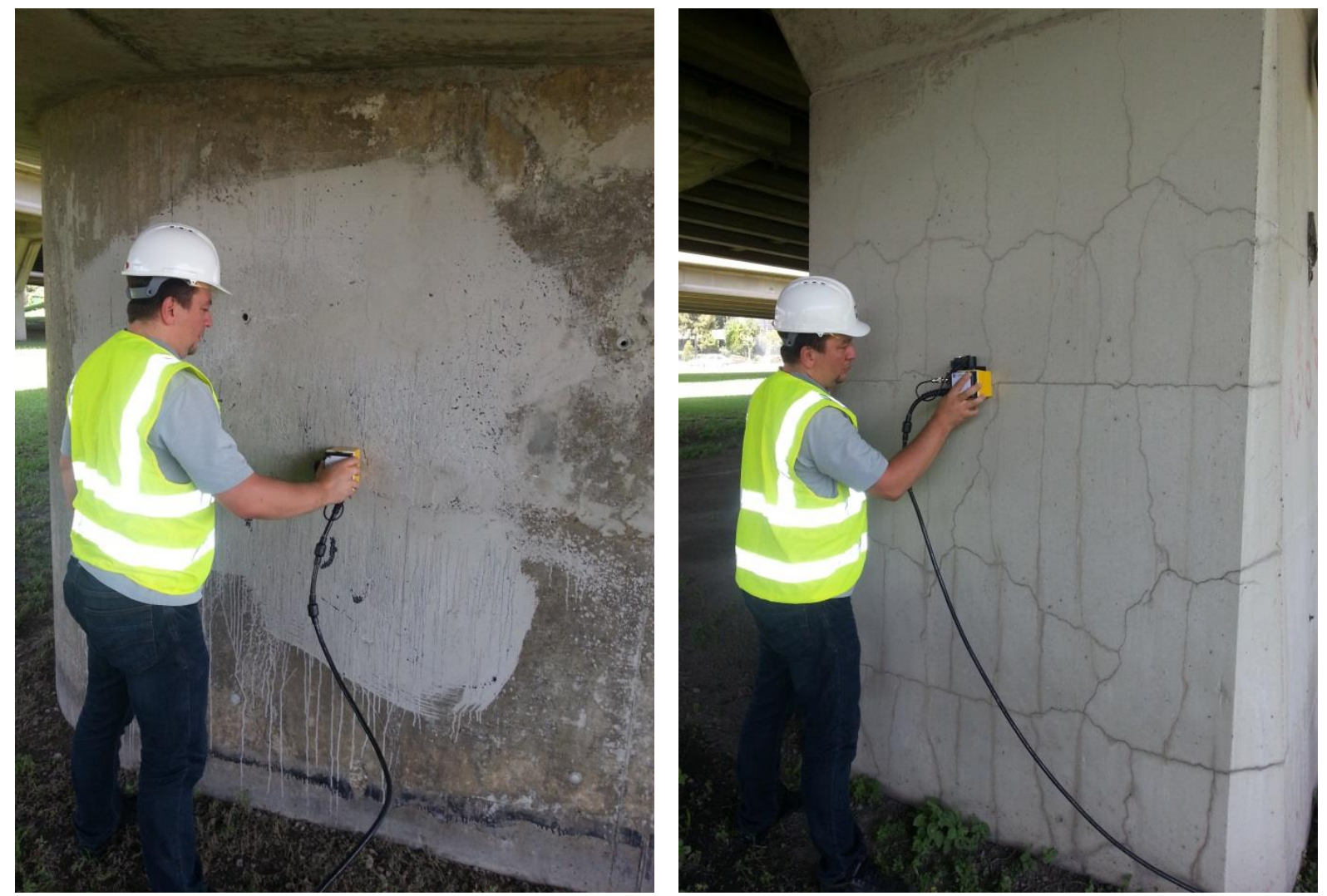

Şekil 2: Köprüsünün taşıyıcı ayağına Yer Radarı Uygulaması

YR TR HF (2 GHz) Anteni ekipmanı mobil ve hafiftir ve yoğun biçimde yüksek kalitede örneklenmiş veri üretebilir (daha yüksek yoğunluklu örnekleme, daha kaliteli tomografi ve 3D veri oluşturur). Yeraltı tabakalarının 2D tomografisini ve incelenen hacmin 3D resmini oluşturmak için IDS GRED veri analizi yazılımı kullanıldı. Hem boylamsal hem enlemsel taramalardan elde edilen veri setlerinin aynı tomografik harita üzerinde birleştirilebilmesi, sonucun güvenilirliğini artırır.

\subsection{KSA PROSEDÜRÜ}

KSA sistemi, yapıların dinamik ve statik kaymalarını ve titreşimlerini ölçen gelişmiş ve hassas bir TMT'dir. Sistem (Şekil 3), bir Kablosuz Sensör ünitesi içerir. Uygun biçimde kullanıldığında, herhangi bir statik veya dinamik yüklemeden kaynaklanan titreşimlerden ötürü meydana gelen kayma ve doğal frekanslar ile ilgili sağlanan veriler, oldukça hassas ve doğru olacaktır [22], [23] , [24] , [25], [26], [27]. 


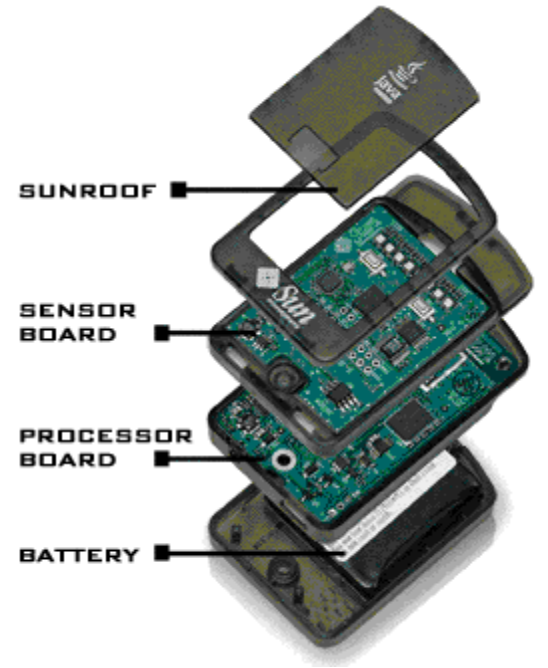

Şekil 3 Oracle SunSPOT Kablosuz Sensörü [17]

KSA teknolojisi kullanımının başlıca avantajı, yapıya kablolarla erişime gerek olmaksızın çok sayıda noktanın uzaktan algılanmasıdır. Şekil 4'te görüldüğü gibi 8 adet KSA aralarında eşit mesafeler konularak uygun yerlere yerleştirildi.

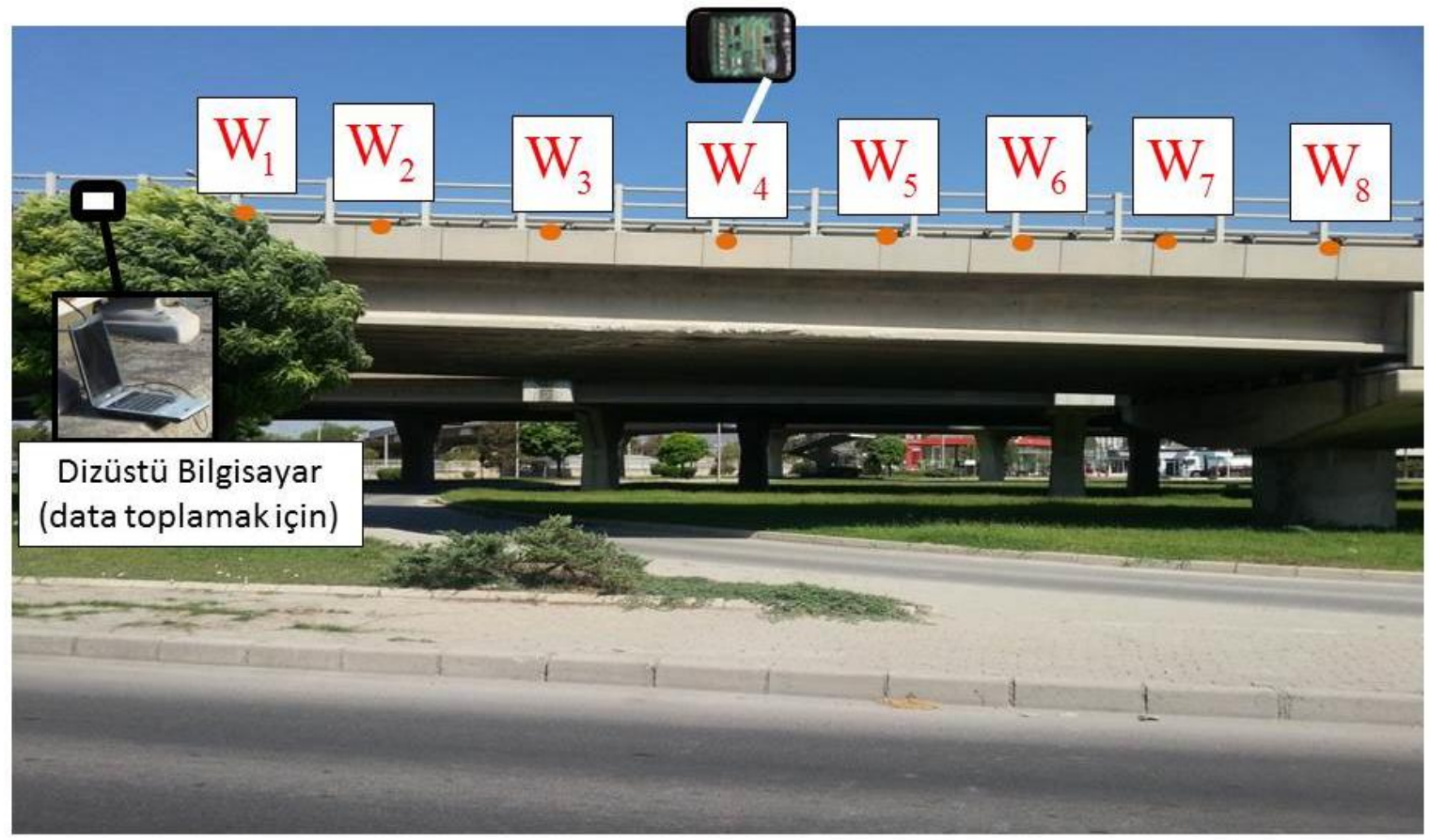

Şekil 4. KSA Sensörleri ve köprüden geçen kamyon [14].

KSA testi 17 Kasım 2013 tarihinde gerçekleştirildi. Hava kuru ve güneşliydi ve sıcaklık $15^{\circ} \mathrm{C}$ idi. Şekil $4^{\prime}$ de görüldüğü gibi, her sinyal kilitlenmesi sırasında yapının uyarılması için 25 tonluk bir araç dört kez köprüden geçirildi. Aracın hızı sabi tutuldu. 


\section{SONUÇLAR}

\subsection{GÖZLE MUAYENE}

YR incelemesine ilaveten, köprü gözle de muayene edildi. Bu denetim pek çok kusurlu alanı ortaya çıkardı. Altan yüksek bir aracın geçerken verdiği hasarlar tespit edilmiştir Bunlardan en kritik olanı, beton çürümesinin, muhtemel donatı korozyonunun, su sızıntısının, üst yüzey bozulmasının ve büyük çatlakların belirgin olduğuydu. Ayrıca beton çürümesinin bir sonucu olarak donatı bozulması olduğu, iyileştirici beton tamiratlarının gerekli olduğu tespit edildi. Gözle muayene bulguları Şekil 5,6 ve 7'de bulunabilir.

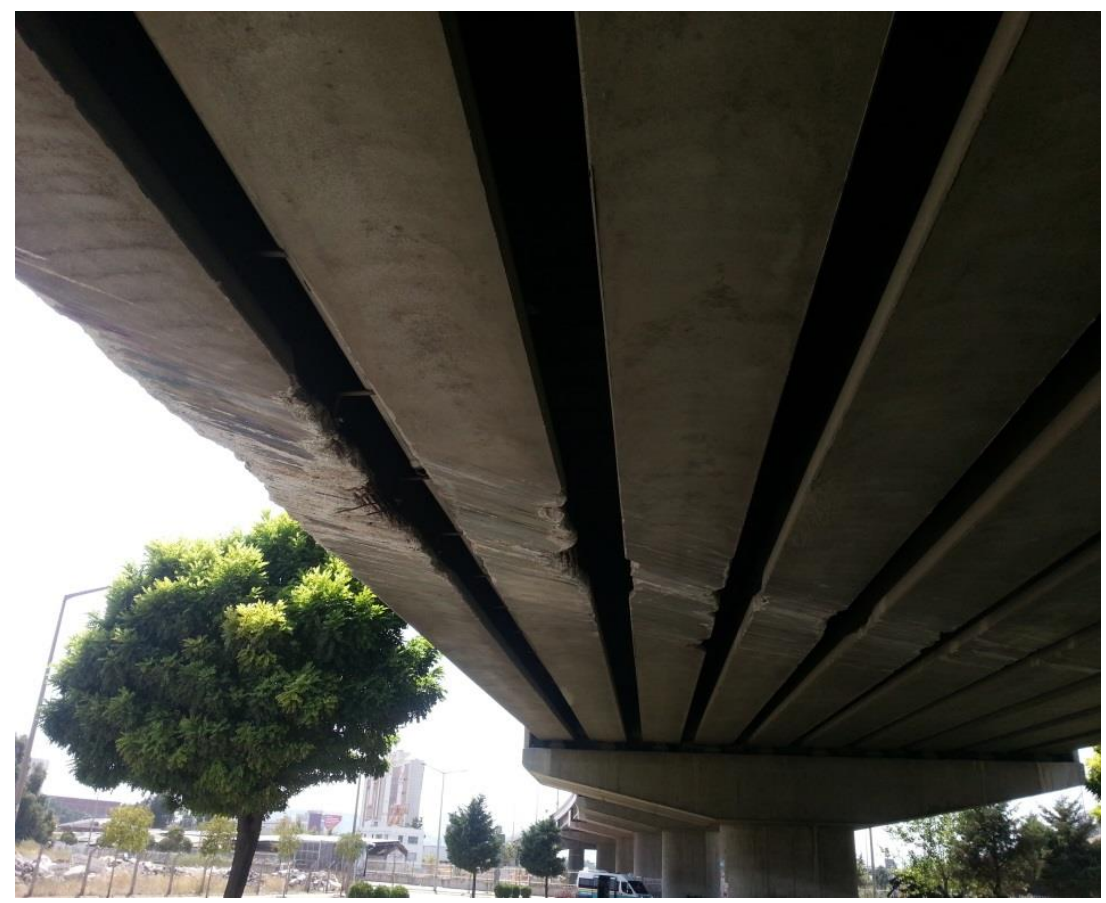

Şekil 5: Köprünün hasarlı bölgesinin alttan görünüşü 


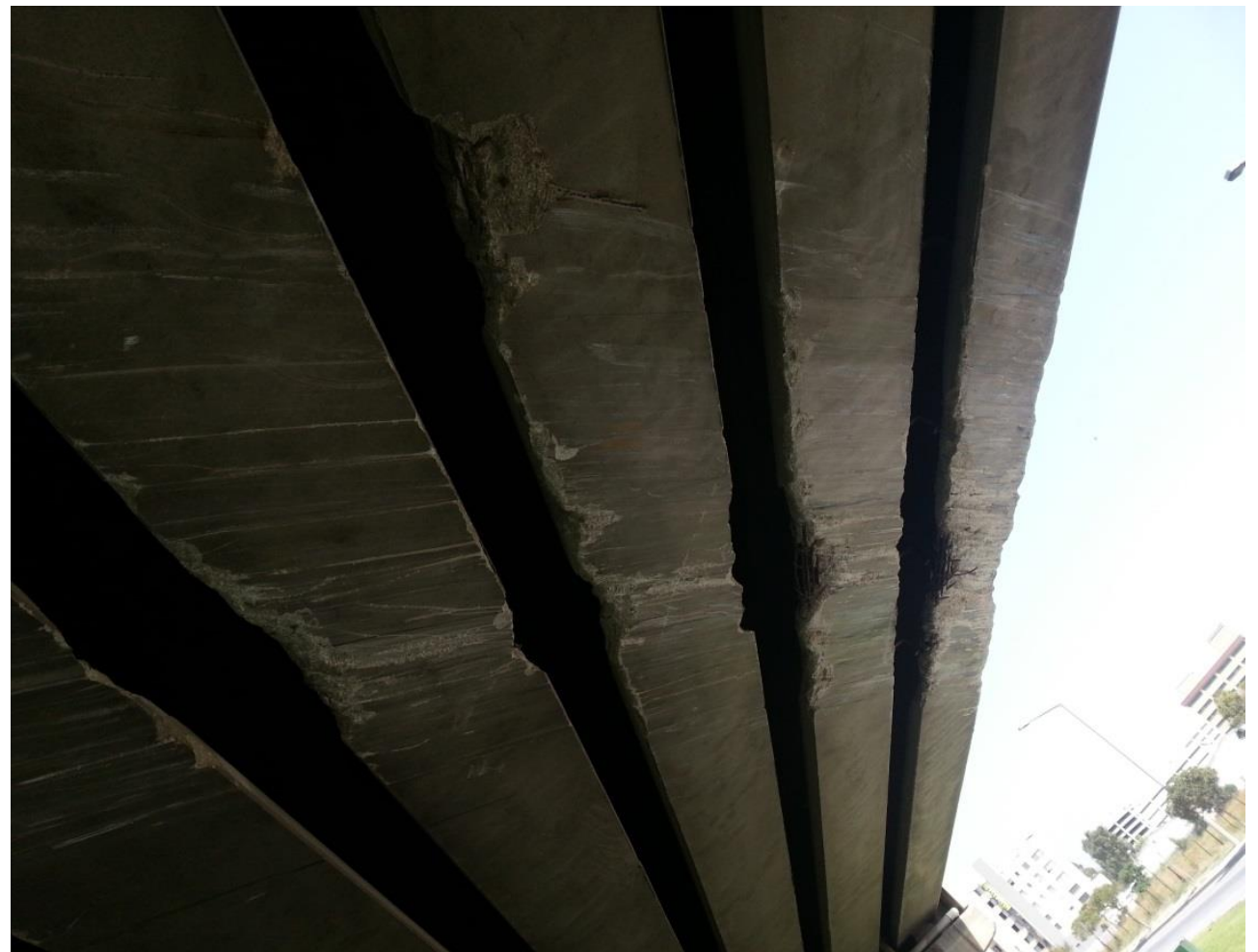

Şekil 6: Köprünün hasarlı bölgesinin alttan görünüşü

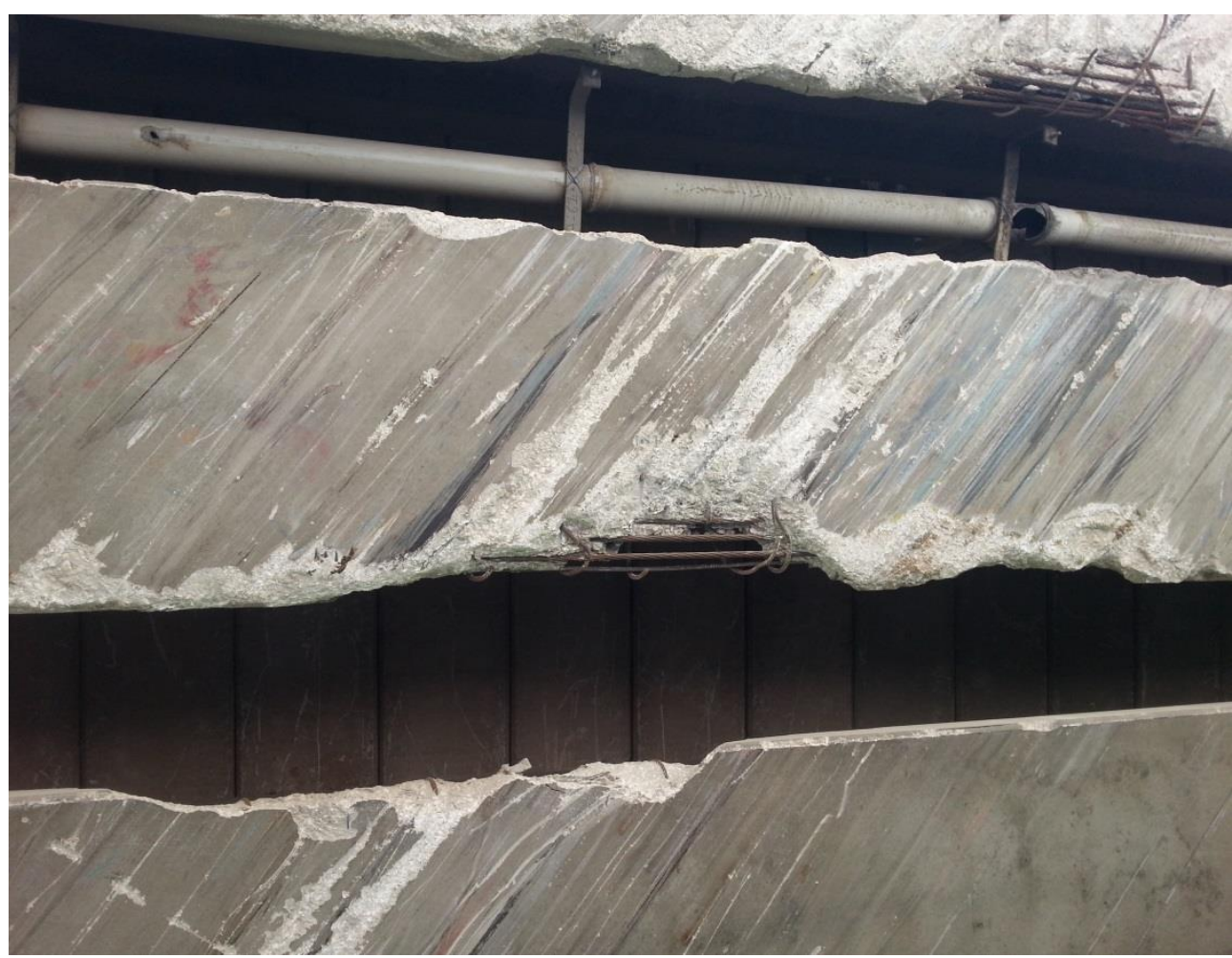

Şekil 7: Köprünün hasarlı bölgesinin beton kırılması ve donatının açığa çıkması 


\subsection{YR İNCELEMESI}

YR kullanılarak köprün analiz edildi fakat bu araştırmanın amaçları için, odak noktalarını teşkil eden köprünün incelenen bölgesi olacaktır (Şekil 8). Bu şekil, incelenen bölgenin merkez kesitinin 0.7 m'lik bir derinliğe kadar olan radargramını göstermektedir.

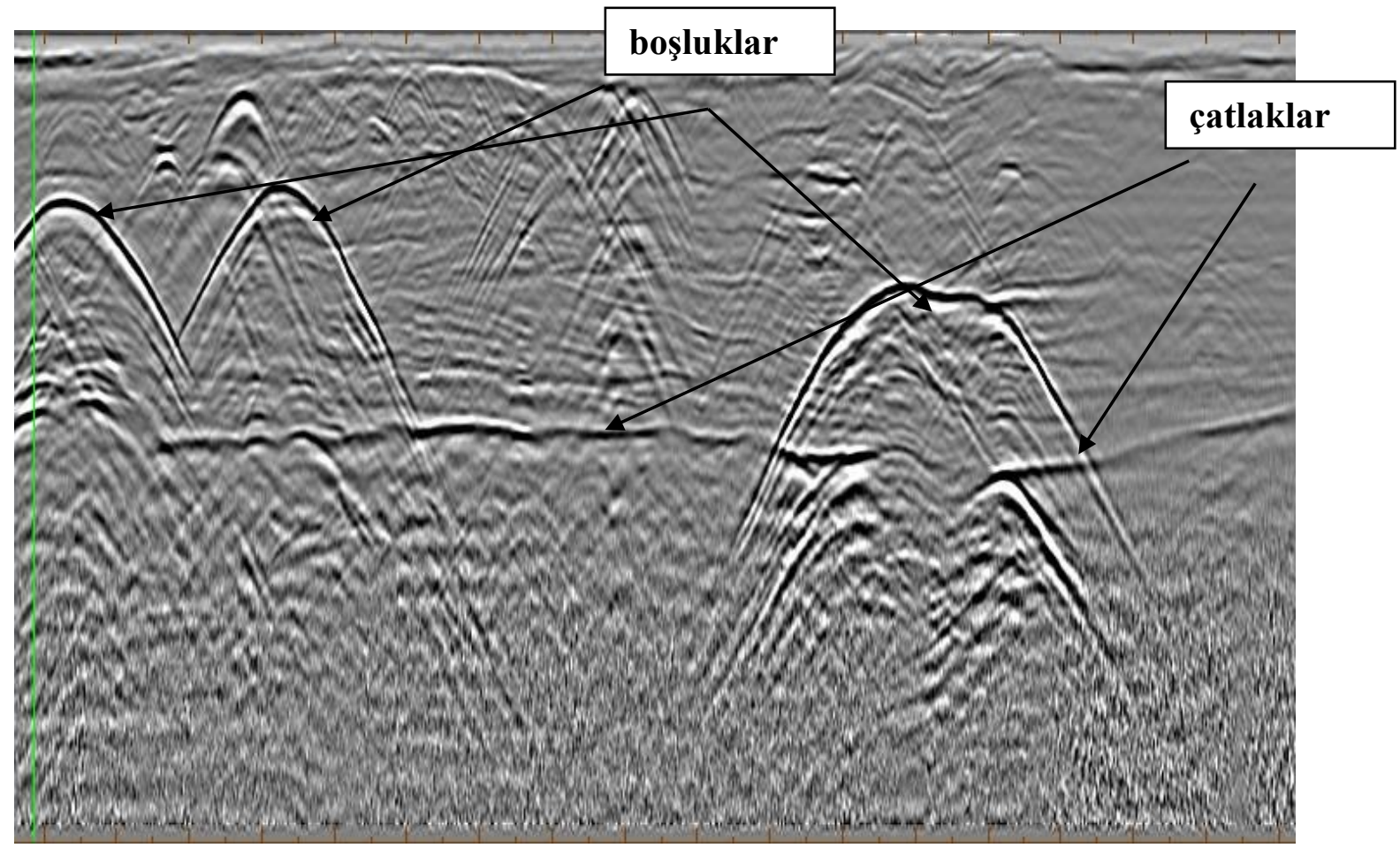

Şekil 8: İşlenen $2 \mathrm{GHz}$ veriler ve köprünün incelenen bölgesindeki daha derin penetrasyonlu başka bir inceleme hattına ilişkin makul açıklamalar (yorumlar) [14].

Nem girişinden etkilenmiş olabilecek muhtemel alanlara sahip boşlukları ve çatlakları yerlerini net olarak gösterir. Şekil 8 ayrıca alt yapısal özellikleri ve muhtemel kısmi bozulmaları resmeder. İşlenen veriler ve müteakip yorumlar, tanımlanan yapısal özellikler ve bileşenler açısından oldukça ikna edicidir. Bölüm 3.2'de belirtildiği gibi, işlenen YR verilerin 3D görüntü olarak sunulması mümkündür (Bkz. Şekil 9). Hem 2D hem 3D görüntüler incelenerek, donatıların konumu ve boyutuna ilişkin doğru karar almak mümkündür. 


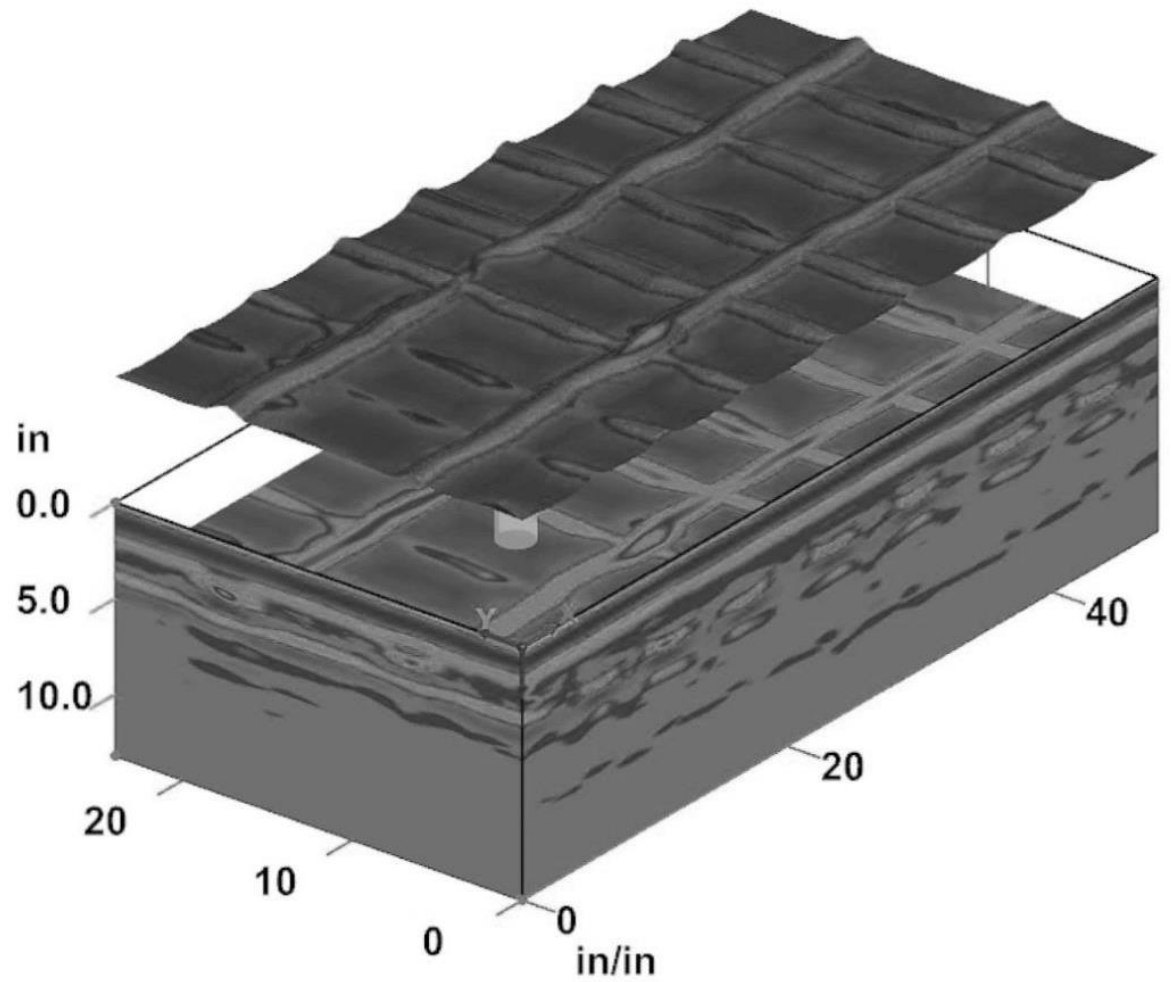

Şekil 9: 3D hacimli işlenmiş veriler [14].

\subsection{KSA GÖZLEMI}

KSA vasıtasıyla, incelenen köprünün maksimum defleksiyonunun köprünün orta aralık arasındaki alanında gerçekleştiği görüldü. Şekil 10, 25 tonluk sabit hızlı yükün bu noktadayken 4 nolu sensördeki maruz kaldığı defleksiyonu gösterir.

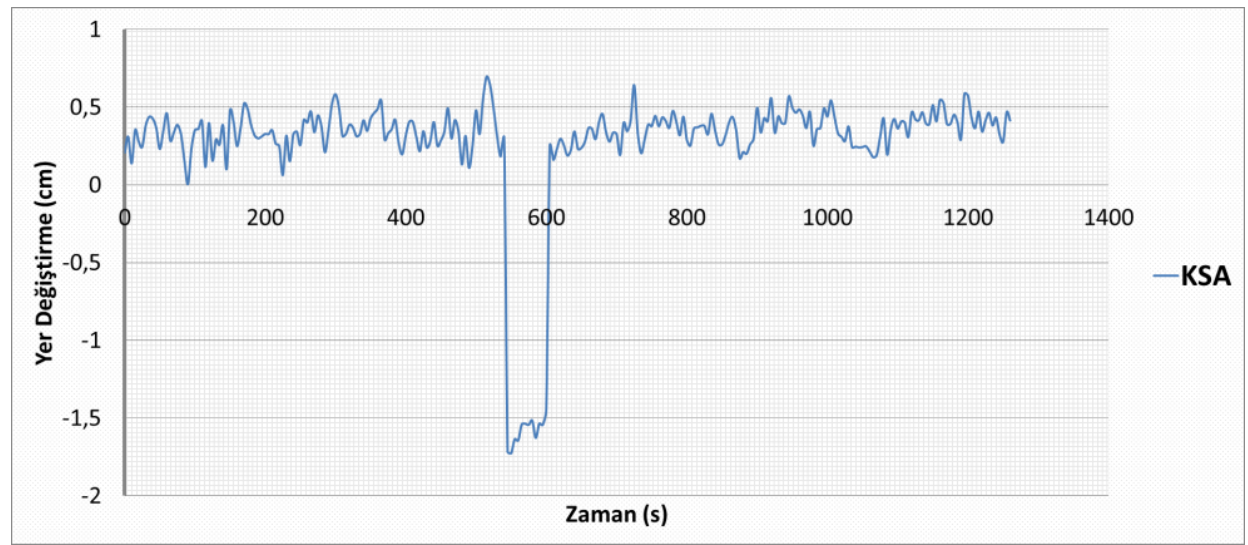

Şekil 10. Hareketli yük geçişi için olan 4 nolu KSA sonuçları [14].

\section{TARTIŞMA}

$\mathrm{Bu}$ belge, örnek olay çalışması köprüsünün dâhili yapısıyla ilgili önceden bilinmeyen bilgilerin (donatı konumu ve muhtemel kusurlar dâhil) nasıl elde edildiğini ve ayrıca köprünün belli bir bölgesinin (Şekil 10) acil onarıma ihtiyacı olduğunun nasıl ortaya 
çıkarıldığını gösteriyor. Bu sonuçlar, köprü sağlı̆̆ının bütün resmi sunularak ve iyileştirici eyleme ilişkin alınacak kararlarla ilgili güven verilerek, harici ve dâhili kusurların aşırı yer değiştirmelerle ilgili olduğu durumlarda karşılaştırma yoluyla elde edildi.

$\mathrm{Bu}$ tümleşik yöntem, köprülerin yapısal değerlendirmesine, donanım ve teknikler açısından mevcut olan sonsuz seçenekten ötürü çoğu kez karmaşık olan bir göreve yönelik güvenilir ve kapsamlı bir araç olarak, yapı işleri endüstrisi için değerlidir. Bu yaklaşım, ek teste gerek olmaksızın (belirtilmedikçe) köprünün sağlam biçimde değerlendirilmesine imkân vererek birbirini tamamlayan TMT yöntemlerini tanımlamak suretiyle bu karmaşıklığı azaltır.

İlk değerlendirmenin uygun maliyetli ve basit oluşu (gözle muayene), daha geleneksel olan sağlık gözetimi yöntemlerine karşı bu tekniğe bir avantaj sağlıyor. Örnek vermek gerekirse, önceden TMT teknikleri çoğu kez bireysel olarak kullanılır ve dolayısıyla mühendislerin aradıkları kapsamlı sağlık değerlendirmesini sağlamazlardı [9], [11], [30]. Örnek köprü üzerinde YR sonuçları, tüm köprü taşıyıc1 sistemleri üzerinde çatlak ve boşlukların olduğunu (Şekil 8 ) fakat bunun köprünün yapısal davranışı üzerindeki etkisinin ne olduğu ve akabinde KSA tekniklerinin uygulanmasıyla hangi bilgilerin sağlandığı konusunun belirsiz olduğunu gösterdi. [3], [8], [12] ile yapılan diğer çalışmalarda, köprü yapıları TMT teknikleri kullanılarak değerlendirildi fakat köprü yapılarının herhangi bir yapısal tepkisi ölçülmediğinden, kapsamlı ve sağlıklı bir değerlendirme yapılamadı. [3], [8], [12] ile detaylandırılan tüm unsurlar belgede de kullanıldı. Fakat geometrik veri toplama işlemi, bağımsız bir rapor, gözle muayene ve bunların yanı sıra köprü yer değiştirmesi (KSA), detaylı iç kompozisyon, donatı konumu (YR) gibi daha başka bilgiler ile gerçekleştirildi. $\mathrm{Bu}$ nedenle, [3], [6], [9], [11], [12] , [29] , [30] ile yapılana kıyasla köprünün çok daha doğru bir yapısal sağlık değerlendirmesinin yapılması mümkün oldu.

$\mathrm{Bu}$ yaklaşım şu an sadece betonarme köprüler için uygundur; örneğin çelik köprüler için uygun değildir. Fakat bazı test yöntemleri (örn. Yer değiştirme gözlemlemeye yönelik KSA) tüm köprü tipleri için uygundur. Yani bazı ayarlamalarla, köprü yapısına özel ek TMT teknikleri kullanılarak bu tümleşik yaklaşım tüm köprü türlerinin değerlendirilmesi amacıyla kullanılabilir.

\section{SONUÇLAR}

Örnek köprü üzerinde uygulanan teknikler, bu tümleşik sağlık gözetimi stratejisinin bir parçası olarak gözle muayeneyi, YR'yi ve KSA'yi kapsarlar. Yapısal kompozisyonuna ilişkin herhangi bir bilgi mevcut olmadığından, seçilen köprü bu araştırma için idealdi. Gözle muayene yapılması üzerine, dirsek bölgesinde belirlenen bazı bozukluklara ilave olarak önemli miktarda çatlak tespit edildi. YR incelemesinin gerçekleştirilmesi üzerine, bu bölgede nem de tespit edildi ve donatı yeri ögrenildi. YR incelemesi ile diğer bölgelerde de nem tespit edildi ve bu sonuçlar diğer test yöntemlerinin sonuçlarıyla karşılaştırılarak, bu nemden en çok etkilenen bölge belirlendi.

Bir köprünün yapısal bütünlüğünün ana göstergelerinden biri, dinamik yük altındaki yer değiştirme seviyesidir ve burada bu ölçünün öğrenilmesi için KSA kullanıldı. YR ve gözle muayene bulgularıyla iyice kıyaslanır halindeydi. Bunların dışındaki test yöntemlerinin herhangi birinin kullanılmasıyla bozulma ve kusurların köprünün dinamik davranışını ne ölçüde etkilediği ortaya çıkarılamayacağı için, bu tümleşik yaklaşımın değeri bu şekilde ortaya koyuldu.

Zaten bahsedilmiş olan nedenlerden ötürü, bir tümleşik yöntemin özellikle örnek köprü 
konusunda yararlı olduğu fakat diğer yapılar için uygulanması açısından da oldukça değerli olduğu kanıtlandı. Yap1 mühendisleri ve araştırmacılar için temel teşkil eden fonksiyon, istikrar ve sağlamlık açısından köprü gibi yapıların davranışlarına dair anlayışımızı derinleştirmesi bakımından, bu yayın mevcut bilgi tabanına katkı sağlamaktadır. 


\section{KAYNAKLAR}

[1] Aït-Mokhtar A., Belarbi R., Benboudjema F., Burlion N., Capra B., Poyet S., 2013, Experimental investigation of the variability of concrete durability properties. Cem Concr Res 2013;45:21-36.

[2] Balayssac JP, Laurens S, Arliguie G, Breysse D, Garnier V, Dérobert X, 2012, Description of the general outlines of the French project SENSO, Quality assessment and limits of different NDT methods. Constr Build Mater 2012; 35:131-8.

[3] Solla M., Lorenzo H., Riveiro B., Rial F.I., 2011, Non-destructive methodologies in the assessment of the masonry arch bridge of Traba, Spain, Engineering Failure Analysis, Volume 18, Issue 3, April 2011, Pages 828-835, ISSN 1350-6307

[4] Rashidi, M \& Gibson, P, 2011 Proposal of a Methodology for Bridge Condition Assessment, Australasian Transport Research Forum, 2011, p 1-13.

[5] Vaghefi K.; Renee C. O.; Devin K. H., A.M.Asce; Theresa (Tess) M. A., M.Asce; Colin N. B.; K. Arthur E.; Christopher R.; Robert S.; Joseph W. B.; Richard D., 2012, Evaluation of Commercially Available Remote Sensors for Highway Bridge Condition Assessment, 10.1061/(ASCE)BE.1943-5592.0000303., 2012, American Society of Civil Engineers.

[6] Nguyen N. T., Sbartaï Z.-M., Lataste J.-F., Breysse D., Bos F., 2013, Assessing the spatial variability of concrete structures using NDT techniques - Laboratory tests and case study, Construction and Building Materials, Volume 49, December 2013, Pages 240250, ISSN 0950-0618

[7] Amos, W., Torgashov, E., Anderson, N., 2009. Bridge deck assessment using ground penetrating radar (GPR). Symposium on the Application of Geophysics to Engineering \& Environmental Problems: Non-destructive Evaluation of Infrastructure, vol. 22, Issue 1.

[8] Solla M., Lorenzo H., Novo A., Caamaño J.C., 2012, Structural analysis of the Roman Bibei bridge (Spain) based on GPR data and numerical modelling, Automation in Construction, Volume 22, March 2012, Pages 334-339, ISSN 0926-5805

[9] Lim M. K. and Cao H., 2013, Combining multiple NDT methods to improve testing effectiveness, Construction and Building Materials, Volume 38, January 2013, Pages 1310-1315, ISSN 0950-0618

[10] Yu, J., Ziehl, P., Zárate, B., Caicedo, J, 2011 Prediction of fatigue crack growth in steel bridge components using acoustic emission, Journal of Constructional Steel Research, Volume 67, Issue 8, August 2011, Pages 1254-1260, ISSN 0143-974X

[11] Sbartaï Z.-M., Breysse D., Larget M., Balayssac J.-P., 2012, Combining NDT techniques for improved evaluation of concrete properties, Cement and Concrete Composites, Volume 34, Issue 6, July 2012, Pages 725-733, ISSN 0958-9465

[12] Lubowiecka I., Armesto J., Arias P., Lorenzo H., Historic bridge modelling using laser scanning, ground penetrating radar and finite element methods in the context of structural dynamics, Engineering Structures, Volume 31, Issue 11, November 2009, Pages 2667-2676, ISSN 0141-0296

[13] Gentile, C., Bernardini, G. \& Ricci, P. P. 2008. A new interferometric radar for fullscale testing of bridges: 2 . Ambient vibration tests and operational modal analysis. Structural faults and repair, 2008. International Conference; 12th, Engineering Technics Press ,Edinburgh, U.K. ISBN: 978-2-35158-061-5

[14] Kilic, Gokhan. 2013. Application of advanced non-destructive testing methods on bridge health assessment and analysis, Ph.D. thesis, 2013, University of Greenwich. 
[15] Alani A. M., Kilic G., Aboutalebi M., 2012. Applications of ground penetrating radar in bridge health monitoring using different frequency antennae systems. EGU General Assembly, Vienna, Austria, p. 12179

[16] Parrillo, R. \& Roberts, R. 2006. Bridge Deck Condition Assessment using Ground Penetrating Radar. ECNDT Geophysical Survey Systems. North Salem, NH, USA. ECNDT 2006 - Tu.4.2.5

[17] Benmokrane, B., El Salakawy, E. F., El Ragaby, A., Desgagné, G. \& Lackey, T. 2004. Design, construction and monitoring of four innovative concrete bridge decks using non corrosive FRP composite bars. Annual Conference \& Exhibition of the Transportation Association of Canada. Québec, Canada.

[18] Rhazi, J., Dous, O., Ballivy, G., Laurens, S. \& Balayssac, J. P. 2003. Non-destructive health evaluation of concrete bridge decks by GPR and half cell potential techniques. 6th International Conference on Nondestructive Testing in Civil Engineering. Berlin.

[19] Alani A. M., Aboutalebi M., Kilic G., 2013. Applications of ground penetrating radar (GPR) in bridge deck monitoring and assessment, Journal of Applied Geophysics, Available online 29 April 2013, ISSN 0926-9851,

[20] ANSYS, 2011, ANSYS 12.1 manual, Inc. (CSI), http:// www1.ansys.com /customer/ content/documentation /ans_cmd.pdf

[21] Bernardini, G., De Pasquale, G., Bicci, A., Marra, M., Coppi, F., Ricci, P. \& Pieraccini, M. 2007. Microwave interferometer for ambient vibration measurement on civil engineering structures: 1 . Principles of the radar technique and laboratory tests. VACES’07 Experimental Vibration Analysis for Civil Engineering Structures. Porto, Portugal.

[22] Wilkins, R., Bastin, G. and Chrzanowski, A., 2003. Alert: A Fully Automated Real Time Monitoring System. Proceedings of the 11th FIG Symposium on Deformation Measurement, Santorini, Greece.

[23] Pieraccini, M., Fratini, M., Parrini, F., Atzeni, C. \& Bartoli, G. 2008. Interferometric radar vs. accelerometer for dynamic monitoring of large structures: An experimental comparison. NDT \& E International, 41, 258-264.

[24] Yu, L., Sepandarmazmomeni M., Godinez, V., Giurgiutiu, V., Ziehl, P. \& Yu, J. 2012. Dual Mode Sensing with Low-Profile Piezoelectric Thin Wafer Sensors for Steel Bridge Crack Detection and Diagnosis. Advances in Civil Engineering, Volume 2012 (2012), Article ID 402179, 10 pages

[25] Kosmatka, Steven H., Kerkhoff, Beatrix, Panarese, William C., 2002, Design and Control of Concrete Mixtures, EB001, Portland Cement Association, 2002, 372 pages.

[26] ACI, 2011 American Concrete Institute 343R-95, Analysis \& Design of Reinforced Concrete Bridge Structures, 2011

[27] AISC, 2006, American Institute of Steel Construction, 13 Edition, ISBN 1-56424$055-X, 2006$

[28] JACOBS LTD., 2010, "Pentagon Road Bridge Visual Inspection Report" 2010

[29] Chopra, A. K. 1995. Dynamics of Structures Theory and Applications to Earthquake Engineering, Prentice Hall, Upper Saddle River, NJ.

[30] Maser, K. R. 2009. Integration of Ground Penetrating Radar and Infrared Thermography for Bridge Deck Condition Evaluation. NDTCE'09, Non-Destructive Testing in Civil Engineering. Nantes, France. 


\section{ÖZGEÇMiș / CV}

\section{Gökhan Kılıç; Yardımcı Doçent Doktor (Asst. Prof. Dr.)}

Gökhan Kılıç, Yıldız Teknik Üniversite'si Mühendislik Fakültesi, İnşaat Mühendisliği ve Eğitim Fakültesi, Bilgisayar ve Öğretim Teknolojisi Eğitimi Bölümlerinden mezun olmuştur. Mezun olduktan sonra, Yıldız Teknik Üniversite'si Geoteknik Anabilim Dalı'nda Araştırma Görevlisi olarak çalışmıştır ve Geoteknik üzerine yüksek lisansını tamamlamıştır. Daha sonra doktora bursu ile İngiltere'de Greenwich Üniversitesi'nde İnşaat Mühendisliği'nde doktora çalışmalarını tamamlamıştır. Bunun yanında, dünyanın önde gelen fïmalarından Black and Veatch'in Londra merkez ofisinde proje mühendisi olarak görev almıştır.

2013 yılında İzmir Ekonomi Üniversitesi'nde Yardımcı Doçent olarak göreve başlamıştır ve halen çalışmaktadır. Aynı zamanda Mühendislik ve Bilgisayar Bilimleri Fakültesi’nde Dekan Yardımcısı olarak görev yapmaktadır. 